\title{
Evaluating additive versus interactive effects of copper and cadmium on Daphnia pulex life history
}

\author{
Shlair A. Sadeq ${ }^{1}$. Andrew P. Beckerman ${ }^{1}$ \\ Received: 4 July 2018 / Accepted: 25 September 2019 / Published online: 25 November 2019 \\ (C) The Author(s) 2019
}

\begin{abstract}
A key challenge of standard ecotoxicological risk assessment is to predict the sub-lethal risk of multiple contaminants on aquatic organisms. Our study assessed the sub-lethal mixture toxicity of copper $(\mathrm{Cu})$ and cadmium $(\mathrm{Cd})$ on Daphnia pulex and included manipulations of food level and assessment of three genotypes. We investigated the interaction between essential $(\mathrm{Cu})$ and non-essential $(\mathrm{Cd})$ metals on ingestion rate, reproduction, maturation time, size at maturity and somatic growth rate of three D. pulex genotypes, over 21 days and under standard and high food conditions. We explored the potential interaction of the metals on ingestion and life history by implementing a response surface experimental design combining control and two levels of $\mathrm{Cu}$ and $\mathrm{Cd}$ and their combinations. Overall, both metals reduced ingestion rates, reduced reproduction, delayed maturation, reduced body size at maturity and lowered somatic growth rate. Our results further indicated pervasive interactions between the metals; numerous instances where the effects of each metal were nonlinear; the effect of a metal varied by D. pulex food levels (ingestion rate and size at maturity), and the effect of a metal varied by genotypes (reproduction). Apart from the maturation time and somatic growth rate, our results suggest that life history traits are affected in non-additive ways by three factors that are often discussed and rarely estimated together: mixtures of metals, genotypes and resource levels. Our data that are derived from exposing daphnids to two metals highlight how metals interact with each other and the context of food resource and genetic variation. While interactions make it harder to generate predictions, and ultimately water quality regulations about the effects of metals, those detected in this study appear to be tractable.
\end{abstract}

Keywords Copper $\cdot$ Cadmium $\cdot$ Daphnia pulex $\cdot$ Genotypes $\cdot$ Life history $\cdot$ Response surface models

\section{Introduction}

Metal toxicity is a worldwide concern arising from natural and anthropogenic discharges such as domestic effluents, agricultural and industrial activities (Ferreira et al. 2008; Shaw et al. 2017). At low and threshold concentrations, metals are known to induce a range of effects on living organisms and their communities, ranging from

Responsible editor: Philippe Garrigues

Shlair A. Sadeq

sasadeq1@sheffield.ac.uk

1 Department of Animal and Plant Sciences, University of Sheffield, Alfred Denny Building, Western Bank, Sheffield S10 2TN, UK reductions in reproduction and growth to associated changes in food web interactions. Their persistence, their non-biodegradability and these associated effects on life history and species interactions ultimately impact on ecosystem services and human health (Monserrat et al. 2007; Nzengue et al. 2011; Piscia et al. 2015).

How stressors such as metals interact with each other and the environment remains a central question in ecology and ecotoxicology because most investigations have historically been limited to single stressors. However, numerous approaches now exist to assess whether the effects of multiple stressors are additive, synergistic or antagonistic, including methods linked to rejecting the null additive models of independent action or concentration addition through response surface experiments designed to detect species traits whether and how interactions among stressors manifest (Barata et al. 2006; 
Ferreira et al. 2008; Laskowski et al. 2010; Pavlaki et al. 2011).

Here, we performed a response surface experiment and evaluated the effects of $\mathrm{Cu}$ and $\mathrm{Cd}$ on feeding rates and four life history traits using $D$. pulex as a model organism. In aquatic communities, $\mathrm{Cu}$ and $\mathrm{Cd}$ are two major stressors among inorganic pollutants and have received much attention in risk assessment regulations (Bellavere and Gorbi 1981; Shuhaimi-Othman et al. 2010; Fernández-Gonzáles et al. 2011). Each metal has a different cellular and potentially ecological mode of action (e.g. impact on life history) because of the differences in each metal's absorbability, solubility, chemical reactivity, transport and formation of complexes within the body (Shanker 2008, Stohs and Bagchi 1995).

At the molecular level, metal-metal interaction is a chemical reaction which can change the oxidation state of the metals, cleave organic radicals and change the state of organometallic compounds (Magos and Webb 1978). In organism's bodies, metal-metal interactions (among essential and non-essential metals) may occur due to the similarity in physical and chemical properties among elements via the mechanisms of ionic and molecular mimicry (Brzóska and Moniuszko-Jakoniuk 2001; Bridges and Zalups 2005). These interactions may cause substantial alterations in the apparent properties of components as well as produce complexes that induce negative effects in organisms (Altenburger et al. 2013). For example, Cd effects arise from interactions with micro- and macroelements (essential analogues) such as $\mathrm{Ca}, \mathrm{Zn}, \mathrm{Cu}$ and Se through ionic mimicry (Feng et al. 2018). Via ionic mimicry, species of a certain metal are able to mimic either the essential element or the cationic form of the element (Zalups and Ahmad 2003). Cadmium can act as an ionic mimic via substitution for other metal ions (mainly $\mathrm{Zn}^{2+}, \mathrm{Cu}^{2+}$ and $\mathrm{Ca}^{2+}$ ) in metalloenzymes (Brzóska and Moniuszko-Jakoniuk 2001). In contrast, molecular mimicry affects the binding of nucleophilic groups of certain biomolecules to metal ions (Zalups 2000). For example, $\mathrm{Cd}$ tends to bind to structures containing - $\mathrm{SH}$ groups, such as enzymes, proteins and nucleic acids (Stohs and Bagchi 1995).

Despite these emerging insights that offer cellular level hypotheses about how interactions (synergy or antagonism) between metals might arise, we still lack robust data on the outcomes of these cellular level effects, including how $\mathrm{Cu}$ and $\mathrm{Cd}$ combine to affect foraging and life history. Here, we focus on identifying whether the effects of $\mathrm{Cu}$ and $\mathrm{Cd}$ are additive or interactive on foraging and life history traits using three genotypes of Daphnia pulex exposed to $\mathrm{Cu}$ and $\mathrm{Cd}$ via a response surface experiment. We further replicated our experiment under standard and high food levels.
Daphnia spp. are a model system for detecting the effects of metal pollution in aquatic environments. They have a significant role in the aquatic food chain linking between algae, higher invertebrates and fish. Given their susceptibility to various contaminants, short generation times, easy culturing and high fecundity rates, they are widely used in experiments (Sarma and Nandini 2006; Colbourne et al. 2011). Furthermore, water flea individuals are clonal, reproducing asexually and populations are typically comprised of many genetically distinct genotypes that can respond differently to environmental pollutants. This makes it possible to explore easily how interactions among stressors may vary among genotypes of Daphnia spp. Several studies have identified substantial genetic variation in response to metals (Baird et al. 1990, 1991; Soares et al. 1992; Barata et al. 1998). Understanding whether there is a genetic variation in response to stressors is crucial to the management of natural water bodies which will typically be populated by multiple genotypes and eco-toxicological test outcomes which often use a single genotype.

Our work here builds on a rich body of literature reporting on the toxicity of each of $\mathrm{Cu}$ or $\mathrm{Cd}$ (Agra et al. 2011; Piscia et al. 2015; Gama-Flores et al. 2006; Guan and Wang 2006; Sadeq and Beckerman 2019). While there is no consistent guideline for the assessment of mixture toxicity, one current approach is to explore how the individual components combine in mixture using the concentration addition (CA) versus independent action (IA) models (Cedergreen et al. 2008). The CA model was historically formulated for exploring how chemicals with similar modes of action combine and assumes that compounds with similar modes of action will behave as if they are simply higher doses of a single compound. Critically, the dose of each compound is expected to combine additively on the response variables. In contrast, the IA model was developed against an assumption that the effects of the compounds, not the compounds themselves, behave additively and typically applies to chemicals with vastly different modes of action, for example, anthropogenic stress versus natural stress (Rodea-Palomares et al. 2015).

Here, based on detail presented above, we assume that $\mathrm{Cu}$ and $\mathrm{Cd}$ operate with different modes of action and that effects may combine additively or with interaction (e.g. the IA assumptions). To assess this, we employ a response surface experiment and analysis, manipulating exposure to single and combined concentrations of each metal. We tested whether mixture concentrations of $\mathrm{Cu}$ and $\mathrm{Cd}$ affect ingestion rate, size at maturity, age at maturity, somatic growth rates and reproduction in an additive versus synergistic manner as revealed by patterns in a response surface, where the life history traits are measured along single and combined concentration gradients of $\mathrm{Cu}$ and Cd. 
A long history of statistical inference from response surface theory forms the basis by which we draw conclusions: additive effects are revealed by planar surfaces, while numerous forms of interactions are revealed by non-linearities in the surfaces. Our use of the response surface approach follows concepts in pharmacology called 'isoboles' (Rodea-Palomares et al. 2015) which do not necessarily depend on mechanistic assumptions (IA versus CA) and are independent of the shapes of the dose-response curves so that they might apply for both CA and IA models of additivity (Berenbaum 1981; Rodea-Palomares et al. 2015). Our approach focuses on attention on life history endpoints. When combined with genetic variation and multiple levels of food, we gain further insight into how natural variation in aquatic communities impacts on our assessment of multiple stressors.

\section{Material and methods}

\section{Daphnia culturing}

Three genotypes of D. pulex, LD33, D86A and D84A, were collected from field populations in the UK and have been in culture for 10 years in the Department of Animal and Plant Sciences, University of Sheffield. These three genotypes have different intrinsic body sizes, life history traits and sensitivity to predation risk (Reger 2013, Reger et al., 2018).

Stock cultures were acclimated in ASTM hard water under controlled conditions of temperature $20 \pm 2{ }^{\circ} \mathrm{C}$, photoperiod 16:8 h light:dark and light intensity 140 lux. Prior to experiments, animals were acclimated to test media over 3 weeks as recommended in the OECD guidelines. The cultures were maintained in 2-L tanks with approximately 25 individuals of each Daphnia genotypes and fed every day with the green algae Chlorella vulgaris fo. viridis (strain number: CAAP 211/12). The algae cultures were grown in Ebert medium (Ebert group, Zoologisches Institut Evolutionsbiologie, Switzerland, n.d.) and kept on a table shaker in a controlled room at $20 \pm 2{ }^{\circ} \mathrm{C}$ under a 16 -h light:8-h dark photoperiod with 173 lux.

\section{Metals preparation}

To prepare metals stock solutions, analytical grade dihydrous copper and cadmium chloride (Fisher Scientific, UK) were dissolved in distilled water and these stocks were used to prepare solutions for the experimental treatments. For chronic toxicity exposures (single and mixture), each treatment concentration (single or combined metals) was prepared daily in 1-L volume ASTM hard water and subsequently delivered into experimental jars. Nominal $\mathrm{Cu}$ concentrations were 0,5 and $10 \mu \mathrm{g} / \mathrm{L}$ and nominal $\mathrm{Cd}$ concentrations were $0,0.5$ and 1 $\mu \mathrm{g} / \mathrm{l}$. These sub-lethal concentrations were chosen based on an extensive literature review (Sadeq and Beckerman 2019) investigating sub-lethal effects of $\mathrm{Cu}$ and $\mathrm{Cd}$ on Cladoceran species. All pair-wise combinations of $\mathrm{Cu}$ and $\mathrm{Cd}$ were assayed, generating a complete response surface grid of nine metal treatments.

\section{Experimental design}

Our exposure tests were performed in accordance with the protocol OECD Daphnia sp. No. 212 (OECD, 2012). Our experimental design follows a completely factorial response surface defined by three genotypes, two food conditions (standard food level $=2 \times 10^{5}$ cells $/ \mathrm{mL}$ and high food level $=5 \times 10^{5}$ cells $/ \mathrm{ml}$ ), and nine metal treatments defined by the three concentrations each of $\mathrm{Cu}$ and $\mathrm{Cd}$ and their combinations. This standard food level has been used for more than a decade with these genotypes (Beckerman et al. 2010; Dennis et al. 2011; Lind and Jeyasingh 2015; Reger et al. 2018).

We replicated each metal treatment $\times$ food level $\times$ genotype combination five times for a total of 270 individuals, each observed over 21 days in 100-mL jars $(9$ metal treatments $\times$ 2 food levels $\times 3$ genotypes $\times 5$ replicates). Animals were fed and media were replaced daily.

Actual metal concentrations, estimated from solutions containing algae food resources, were calculated using a separate set of replicate jars using ICP-MS (Inductively coupled plasma mass spectrometry; Agilent 4500; accuracy < $1 \mathrm{ng} / \mathrm{L}$ ). We estimated realised concentration in media preparations that were prepared exactly as our daily preparations for experiment (see above). Realised concentrations did not deviate from nominal concentrations (linear regression; $n=3$ per metal concentration; assay 12 hours after media preparation; $\mathrm{Cu}$ : $R^{2}=0.99, F=1913, p<0.002$; Cd: $R^{2}=0.98, F=996, p<$ 0.002 ).

\section{Life history traits}

We measured five traits in the daphnids over the 21-day experimental period: ingestion rate, size at maturity, age at maturity, somatic growth rate and reproduction as the sum of three clutches. Life history traits in all treatments were assessed by daily observation during the transfer to new media in new jars. Photographs were taken under a microscope Leica MZ6 modular stereomicroscope $(\mathrm{GmbH}$, Wetzler, Germany) with a Cannon EOS 350D DSLR camera. Size at maturity was measured from the top of the head to the base of the carapace spine using ImageJ (Hooper et al. 2006; Beckerman et al. 2010). Age and size at maturity were estimated on the day neonates first appear in the 
brood pouch. Reproductive output was recorded by counting neonates produced over three clutches. Somatic growth rate was calculated as $\ln$ (size at maturity/initial size)/(age at maturity (days)).

Ingestion rate was measured on animals at their day of maturity in all treatments. As media was replaced daily with known food concentrations, this is a straightforward assay recording algae concentration on transfer to the new media and 24 hours later before transfer to new media again. It was calculated as the number of algae cells digested by daphnids over $24 \mathrm{~h}$ (cells/h) (final measurement (after $24 \mathrm{~h})$ - initial measurement (0 time)) using spectrophotometry at wavelength $440 \mathrm{~nm}$. (Ferrando and Andreu 1993; Beckerman et al. 2007).

\section{Statistical analysis}

For each trait, we implemented the following analysis pipeline that maps onto our experimental design. We fit a response surface model that combined first order main effects of $\mathrm{Cu}$ and $\mathrm{Cd}$, second order polynomials of $\mathrm{Cu}$ and $\mathrm{Cd}$, and the interaction between $\mathrm{Cu}$ and $\mathrm{Cd}$. This is the classic response surface model used to reveal additive and several forms of interactive (synergistic/antagonistic) effects on the life history endpoints (Khuri and Cornell 1996). We combined this standard response surface model with the main effects of, and interaction between, algae food levels and daphnia genotype, algae levels and each of the metals, and daphnia genotype and each of the metals. Our statistical model is thus defined as

Trait $\sim\left(\mathrm{Cu}+\mathrm{Cu}^{2}+\mathrm{Cd}+\mathrm{Cd}^{2}+\mathrm{Cu} * \mathrm{Cd}\right)+$

Food Level + Genotype +

$(\mathrm{Cu} *$ Food level $)+(\mathrm{Cd} *$ Food level $)+$

$(\mathrm{Cu} *$ Genotype $)+(\mathrm{Cd} *$ Genotype $)+$

(Food Level * Genotype)

The terms in the first line define the classic response surface model that allows for planar or non-linear shapes to be detected over the nine treatment combinations for each metal. The second line identifies the additional main effects of food level and genotype and the third-fifth line, the interactions between these terms and between them and the metals. This model allows us to answer the questions a) does the effect of $\mathrm{Cu}$ on trait vary by $\mathrm{Cd}$ ?, b) is the effect of $\mathrm{Cu}$ or $\mathrm{Cd}$ non-linear?, c) does the effect of $\mathrm{Cu}$ or $\mathrm{Cd}$ vary by food level?, d) does the effect of $\mathrm{Cu}$ or Cd vary by genotype? and e) does the effect of food level vary by genotype?

All data were analysed using the statistical software programme R (R Core team, 2013) version 3.4.2. We fit the model using the $1 \mathrm{~m}$ function (linear model) in $\mathrm{R}$ followed by Type II sums of squares implemented by the Anova function in the car package for $\mathrm{R}$ for significance testing.

\section{Results}

In each of the following sections, we report for each trait on interactions between $\mathrm{Cu}$ and $\mathrm{Cd}$, algae levels and genotype, algae levels and the metals, and genotype and the metals for each measured trait. The results for each trait are visualised by a set of six contour plots graphically depicting the shape of the estimated response surface among genotypes and between food levels; each response surface is defined by a set of contours and colours representing fitted/predicted values from the model. Note that in all presentations of the effect of interactions, the ':' is used to represent the interaction.

As expected from previous research and life history theory linked to reduced energy intake, $\mathrm{Cu}$ and $\mathrm{Cd}$ lowered ingestion, lowered reproduction, delayed maturation, reduced size at maturity and reduced somatic growth rate. These general patterns, however, are underpinned by several interactions among metals and food, metals and genotype, and food and genotype. In the following sections, we detail these interactions and provide associated visualisations of the response surfaces.

\section{Ingestion rate}

Overall, ingesting rate decreased with increasing $\mathrm{Cu}$ and $\mathrm{Cd}$ (Fig. 1). The effects of $\mathrm{Cu}$ and $\mathrm{Cd}$ on ingestion rates are defined by several interactions (Fig. 1). The two metals interact to shape ingestion rate; the effect of $\mathrm{Cu}$ on ingestion varied by $\mathrm{Cd}$ in all genotypes $(\mathrm{Cu}$ :Cd interaction; $F=$ $54, \mathrm{df}=1, p<0.01$ ). Furthermore, the effect of $\mathrm{Cd}$, but not $\mathrm{Cu}$, was non-linear, as indicated by the significant $\mathrm{Cd}^{2}$ term $\left(F=10.15, \mathrm{df}=2, p<0.01 ; \mathrm{t}-\mathrm{Cu}^{2}=-0.11, p=\right.$ $\left.0.9, \mathrm{t}-\mathrm{Cd}^{2}=4.2, p<0.01\right)$. This led to the lowest levels of ingestion occuring at the highest levels of $\mathrm{Cu}$ but not $\mathrm{Cd}$.

The effect of $\mathrm{Cu}$ and $\mathrm{Cd}$ also varied by food levels (F$\mathrm{Cu}$ :food level $=5.08, \mathrm{df}=1, p=0.025, \mathrm{~F}-\mathrm{Cd}$ :food level $=$ $11.9, \mathrm{df}=1, p<0.01)$. Ingestion declined more with increasing $\mathrm{Cu}$ and $\mathrm{Cd}$ at high food. In fact, ingestion under metal stress at high foods is reduced to control ingestion rates under low food.

In contrast to the above interactions, the effect of $\mathrm{Cu}$ and $\mathrm{Cd}$ on ingestion did not vary by genotype (F-Cu:genotype $=$ $0.7, p=0.49 ; \mathrm{F}-\mathrm{Cd}$ :genotype $=0.23, p=0.79)$. However, the genotypes differ in their average rate of ingestion $(F=3.76, p$ $=0.025$ ).

\section{Reproduction}

Reproduction declined with increasing $\mathrm{Cu}$ and $\mathrm{Cd}$. The effects of $\mathrm{Cu}$ and $\mathrm{Cd}$ on reproduction are defined by several interactions (Fig. 2). The effect of $\mathrm{Cu}$ on reproduction 
Fig. 1 Contour plots for the effect of $\mathrm{Cu} / \mathrm{Cd}$ mixture on the ingestion rate $(\mathrm{cell} / \mathrm{h})$ of different genotypes of $D$. pulex. The plots display the fitted (predicted) values from the response surface model. Each panel is a genotype-food combination and the $\mathrm{x}$ - and $\mathrm{y}$-axes are the concentrations of the metals. Yellow versus red colours are higher values of ingestion. Details of significant terms that underpin the shapes that can be seen are described in the text

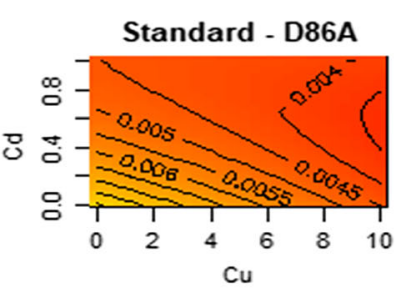

High - D86A

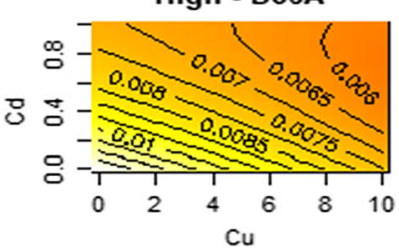

$\mathrm{Cu}$

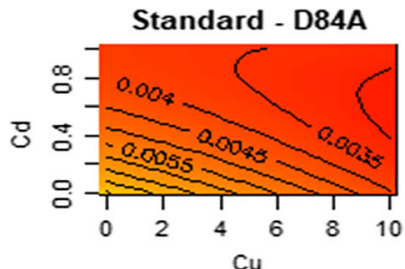

High - D84A

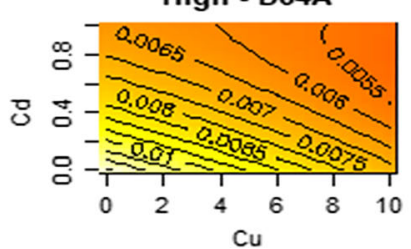

of $D$. pulex varied by $\mathrm{Cd}$; the two metals interact to shape reproduction $(\mathrm{Cu}: \mathrm{Cd}$ interaction; $F=194$, $\mathrm{df}=2, p<0.01)$. Further, the effects of $\mathrm{Cu}$ and $\mathrm{Cd}$ were non-linear, defined by significant squared terms for each $(F=18.8, \mathrm{df}=2, p<$ $\left.0.01 ; \mathrm{t}-\mathrm{Cu}^{2}=3.1, p=0.01, \mathrm{t}-\mathrm{Cd}^{2}=3.7, p<0.01\right)$. Thus, the lowest levels of reproduction occur at the highest levels of $\mathrm{Cd}$, but not $\mathrm{Cu}$.

The effect of $\mathrm{Cu}$ and $\mathrm{Cd}$ on reproduction varied by genotype $(\mathrm{F}-\mathrm{Cu}$ :genotype $=5.7, p=0.004 ; \mathrm{F}$ Cd:genotype $=4.6, p=0.01)$. However, The effect of each metal on reproduction did not vary by food levels $(\mathrm{F}$ $\mathrm{Cu}$ :food level $=0.65, \mathrm{df}=1, p=0.42, \mathrm{~F}-\mathrm{Cd}$ :food level $=0.03, \mathrm{df}=1, p<0.84)$.

\section{Maturation time}

$\mathrm{Cu}$ and $\mathrm{Cd}$ delayed maturation. The effects of $\mathrm{Cu}$ and $\mathrm{Cd}$ on maturation time are defined by several interactions (Fig. $3)$. The effect of $\mathrm{Cu}$ on maturation time varied by $\mathrm{Cd}$ (Cu:Cd interaction; $F=84, \mathrm{df}=1, p<0.01)$. We detected only linear effects of $\mathrm{Cu}$ and $\mathrm{Cd}(F=0.28, \mathrm{df}=2, p<0.76$; $\left.\mathrm{t}-\mathrm{Cu}^{2}=0.66, p=0.51, \mathrm{t}-\mathrm{Cd}^{2}=0.07, p<0.94\right)$. Figure 3 indicates that maturation was delayed more strongly by $\mathrm{Cd}$ than $\mathrm{Cu}$.

$\mathrm{Cu}$ and $\mathrm{Cd}$ effects did not vary by food levels (F$\mathrm{Cu}$ :food level $=1.81, \mathrm{df}=1, p=0.27, F$-Cd:food level $=$ 0.21 , df $=1, p<0.64)$ or by genotypes (F-Cu:genotype $=$ $1.84, p=0.16 ; F$-Cd:genotype $=0.54, p=0.58)$. Maturation was earlier on high food $(F=35.22, \mathrm{df}=1, p$ $<0.001)$. Genotypes did not differ in their maturation time with food levels $(F=0.4, p=0.67)$.

\section{Size at maturity}

Size at maturity declined with increasing $\mathrm{Cu}$ and $\mathrm{Cd}$ concentrations. The effects of $\mathrm{Cu}$ and $\mathrm{Cd}$ on size at maturity are defined by several interactions (Fig. 4). The effect of $\mathrm{Cu}$ on size at maturity varied by $\mathrm{Cd}$; size reductions caused by $\mathrm{Cd}$ were less pronounced at high levels of $\mathrm{Cu}(\mathrm{Cu}: \mathrm{Cd}$ interaction; $F=145.1, \mathrm{df}=1, p<0.01)$. We detected only linear effects of $\mathrm{Cu}$ and $\mathrm{Cd}\left(F=0.35, \mathrm{df}=2, p<0.70 ; \mathrm{t}-\mathrm{Cu}^{2}=0.4, p=0.68\right.$, t$\left.\mathrm{Cd}^{2}=0.52, p<0.6\right)$. The effect of $\mathrm{Cu}$ and $\mathrm{Cd}$ on size at maturity varied by food level $(\mathrm{F}-\mathrm{Cu}$ :food level $=8.47, \mathrm{df}=$ $1, p=0.004, \mathrm{~F}-\mathrm{Cd}$ :food level $=8.68, \mathrm{df}=1, p<0.003)$. The effect on size at maturity of each metal did not vary by genotype (F-Cu:genotype $=2.64, p=0.07 ; \mathrm{F}-\mathrm{Cd}$ :genotype $=0.01$, $p=0.98)$. Average size at maturity did not vary by genotype $(F=0.54, p=0.59)$.

\section{Somatic growth rate}

Growth rates were significantly lower with increasing $\mathrm{Cu}$ and $\mathrm{Cd}$. The effects of $\mathrm{Cu}$ and $\mathrm{Cd}$ on somatic growth rate were defined by several interactions (Fig. 5). The effect of $\mathrm{Cu}$ on somatic growth rate varied by $\mathrm{Cd}(\mathrm{Cu}: \mathrm{Cd}$ interaction; $F=$ 214.85 , df $=1, p<0.01)$. We detected a non-linear effect of $\mathrm{Cd}$ concentration, but not $\mathrm{Cu}\left(\mathrm{t}-\mathrm{Cu}^{2}=1.92, p=0.56, \mathrm{t}-\mathrm{Cd}^{2}=\right.$ $4.41, p<0.01)$. The effect of $\mathrm{Cu}$ and $\mathrm{Cd}$ did not vary by food levels (F-Cu:food level $=0.15, \mathrm{df}=1, p=0.7, \mathrm{~F}-\mathrm{Cd}$ :food level $=0.82, \mathrm{df}=1, p<0.37)$. Furthermore, the effect of $\mathrm{Cu}$ and $\mathrm{Cd}$ on somatic growth rate did not vary by genotype $(\mathrm{F}$ Cu:genotype $=0.08, p=0.92 ; \mathrm{F}-\mathrm{Cd}$ :genotype $=0.71, p=$ $0.53)$. Genotypes did not differ in their average growth rate $(F=0.09, p=0.91)$.

\section{Discussion}

Evaluation of the effect of metal mixtures at sub-lethal levels on life history traits of organisms in aquatic communities is of particular importance to the assessment of ecosystem services (e.g freshwater, recreation), to chemical risk assessment and subsequently, to water quality criteria. In the last few decades, metal pollution has 
Fig. 2 Contour plot for the effect of $\mathrm{Cu} / \mathrm{Cd}$ mixture on reproduction (mean number of neonates per female) across three genotypes of D. pulex. The plots display the fitted (predicted) values from the response surface model. Each panel is a genotype-food combination and the $\mathrm{x}$ - and $\mathrm{y}$-axes are the concentrations of the metals. Yellow versus red colours are higher values of reproduction. Details of significant terms that underpin the shapes that can be seen are described in the text

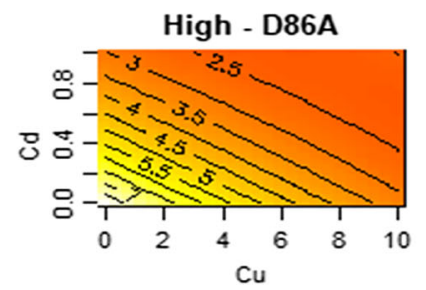

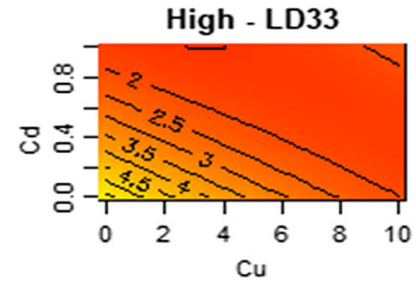

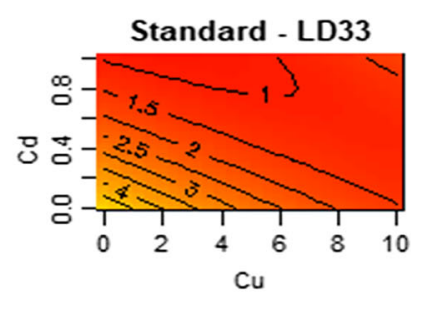

drawn much attention due to their persistence and deleterious effects on aquatic food chains. Though there has been considerable exploration into the toxicity of $\mathrm{Cu}$ and $\mathrm{Cd}$ on aquatic organisms, particularly Cladocera, the majority of work has focused on single stressors and single genotypes under standardised conditions that are beneficial to a testing environment but not always reflective of natural communities (Brix et al. 2001; Barata et al. 2002; Griffitt et al., 2008; Sadeq and Beckerman 2019). Assessing the interaction among stressors (metals), the role of genetic variation and the impact of variation in food levels remain a key agenda in ecological and ecotoxicological risk assessment.

We assessed the presence of additive versus interactive effects of the metals $\mathrm{Cu}$ and $\mathrm{Cd}$ on life history of three $D$. pulex genotypes under two food conditions. We employed a response surface experimental design to capture patterns of additive or interactive effects in ingestion rates and life history traits of three D. pulex genotypes via a

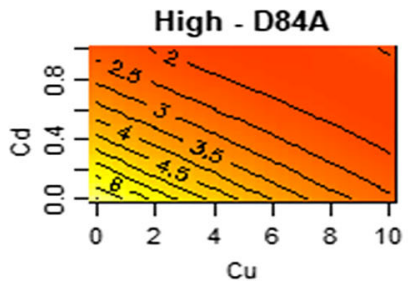
年
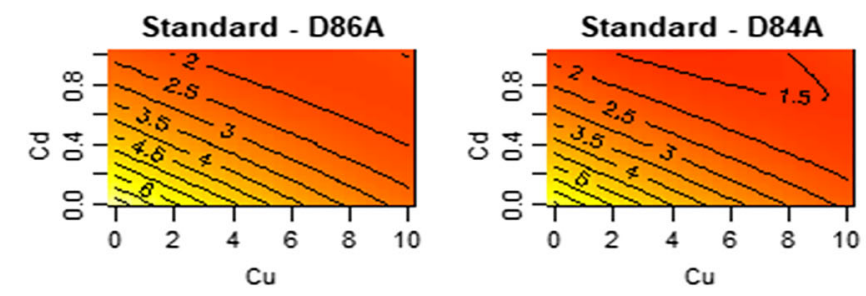

chronic exposure experiment over 21 days. We focused on five classic ecological endpoints linked to daphnid biology and impact in aquatic communities: ingestion rate, reproduction, age at maturity, size at maturity and somatic growth rate.

Despite the presence of several interactions (among stressors, genotypes and food levels), our data indicate (Figs. 1, 2, 3, 4 and 5) that the overall presence of two metals reduced ingestion rates, impaired reproduction, extended the time to maturation, reduced size at maturity and lowered somatic growth rates. The non-linearities we detect do not, we suggest, paint too complex a picture for understanding the combined effects of $\mathrm{Cu}$ and $\mathrm{Cd}$. Figures 1, 2, 3, 4 and 5 do not show peaks or troughs of responses at sub-lethal levels of $\mathrm{Cu}$ and $\mathrm{Cd}$. There are no saddle points that arise across the concentrations. In general, combined effects of $\mathrm{Cu}$ and $\mathrm{Cd}$ equate with increases or decreases in the traits we have measured and thus indicate in summary what logic and conventional thinking

Fig. 3 Contour plot for the effect of $\mathrm{Cu} / \mathrm{Cd}$ mixture on the maturation age (days) of different genotypes of $D$. pulex. The plots display the fitted (predicted) values from the response surface model. Each panel is a genotype-food combination and the $\mathrm{x}$ - and $\mathrm{y}$ axes are the concentrations of the metals. Yellow versus red colours are later maturation times. Details of significant terms that underpin the shapes that can be seen are described in the text
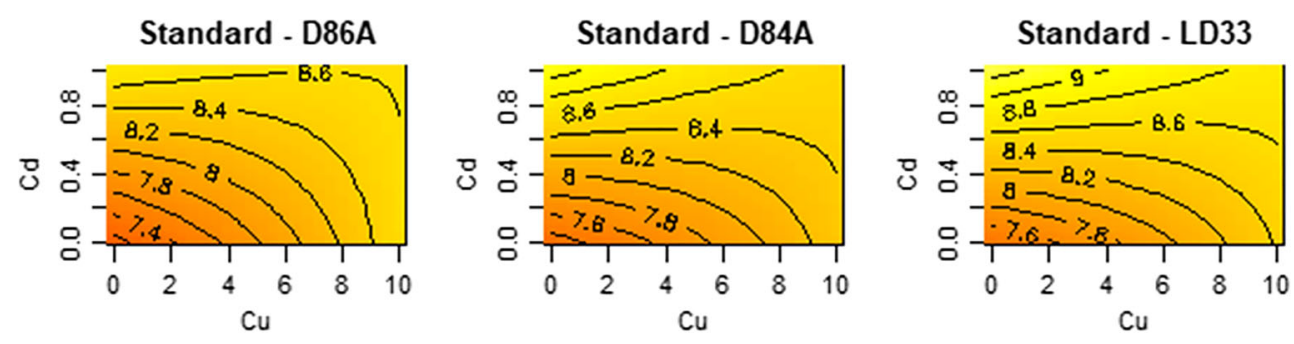

High - D86A

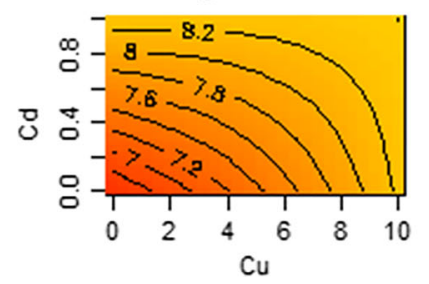

High - D84A

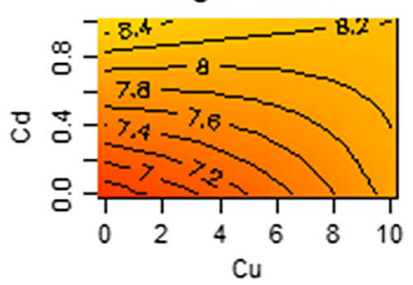

High - LD33

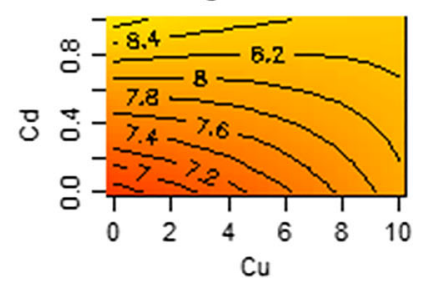


Fig. 4 Contour plot for the effect of $\mathrm{Cu} / \mathrm{Cd}$ mixture on body size at maturity $(\mathrm{mm})$ across three genotypes of $D$. pulex. The plots display the fitted (predicted) values from the response surface model. Each panel is a genotype-food combination and the $\mathrm{x}$ - and $\mathrm{y}$ axes are the concentrations of the metals. Yellow versus red colours are larger size at maturity. Details of significant terms that underpin the shapes that can be seen are described in the text
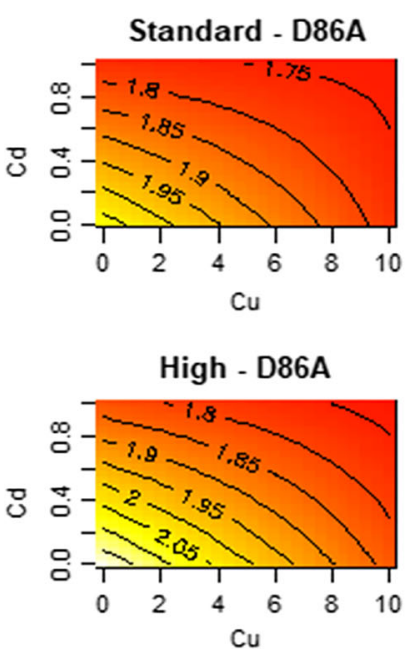

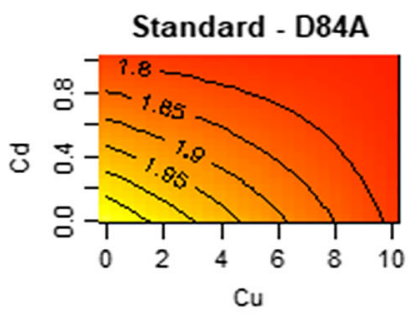

High - LD33

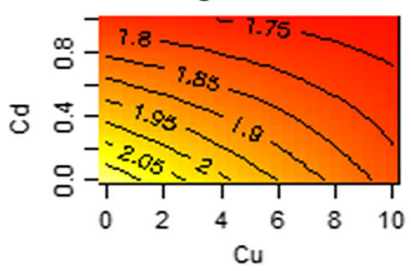

Standard - LD33

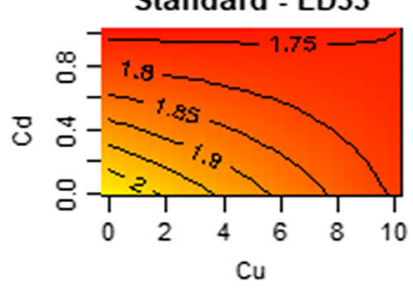

High - D84A

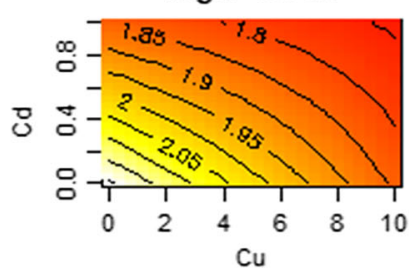

dictate: a combination of $\mathrm{Cu}$ and $\mathrm{Cd}$ are substantially worse for Daphnia performance.

While, our findings showed a variation in the interaction between metals and food levels and metals and genotypes across traits, our data highlight the importance of context in assessment of life history endpoints in response to different stressors. With respect to $\mathrm{Cu}$, which is known to interfere with digestion, we expected and found that the effect of $\mathrm{Cu}$ on ingestion rates varied by food. We also found this pattern of effect for Cd. Metals disrupt digestive physiology, which is linked to energy intake and hence resources acquired for growth and reproductive activities (Barata and Baird 2000; Bui et al. 2016). The relationships between energy intake and the life history traits (more food should increase size at maturity, reduce age at maturity, increase reproduction and increase somatic growth rate)

suggests that the interaction between metals and food we see for these traits may arise in part via these relationships between life history and food.

Our work contributes to a growing literature investigating the effects of metal mixtures and Daphnia spp. For example, in recent research, binary mixtures of nickel $(\mathrm{Ni})$, zinc $(\mathrm{Zn}), \mathrm{Cu}$ and $\mathrm{Cd}$ produced a more than additive effect on food consumption rate of Daphnia magna at low concentration of metals (Lari et al. 2017). Inter-clonal variation in D. magna was found in the response of ingestion rate to $\mathrm{Cd}$ and temperature (Muyssen and Janssen 2010). This body of data suggests a key role of foraging and digestion in metal effects. Compounding these effects, under metal exposure, organisms may also spend more energy to increase their tolerance (Calow 1991). Supporting our data on reproduction, growth and

Fig. 5 Contour plot for the effect of $\mathrm{Cu} / \mathrm{Cd}$ mixture on somatic growth rate $\mathrm{g}\left(\mathrm{d}^{-1}\right)$ of different genotypes of $D$. pulex. The plots display the fitted (predicted) values from the response surface model. Each panel is a genotypefood combination and the $\mathrm{x}$ - and $y$-axes are the concentrations of the metals. Yellow versus red colours are higher growth rates. Details of significant terms that underpin the shapes that can be seen are described in the text
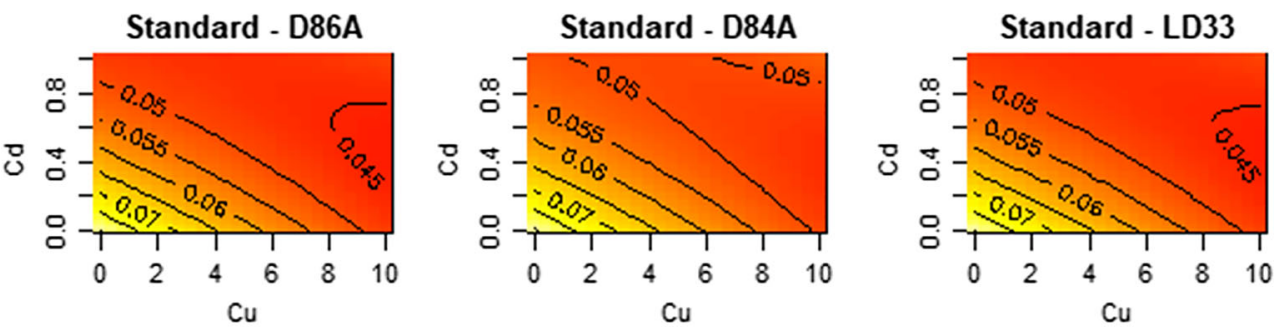

High - D86A

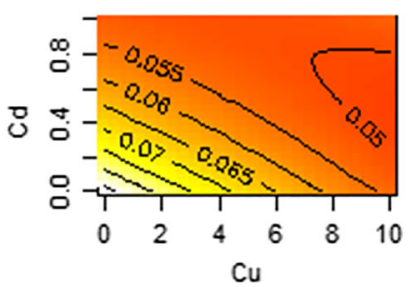

High - D84A

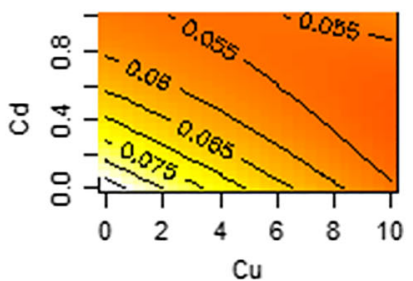

High - LD33

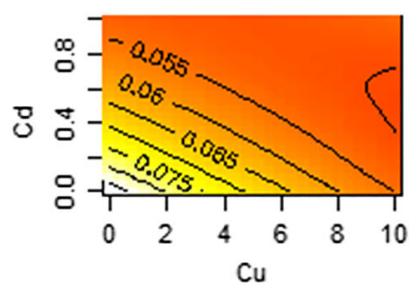


maturity, data also suggest changes in allocation to growth and reproduction that effect life history responses depending on duration and exposure concentration (Muyssen and Janssen 2001; Bossuyt and Janssen 2004; Canli, 2006; Durou et al. 2005).

Detecting consistency in the type of response (additive, synergistic, antagonistic) is proven challenging. A recent meta-analysis evaluating $\mathrm{Cu}, \mathrm{Cd}$ and $\mathrm{Zn}$ toxicity showed variable interactions for many endpoints measured under the same experimental conditions. The effects were strongly associated with the identity of the endpoint on which the metal combinations were tested (Vijver et al. 2011). Similarly, different patterns of responses have been observed in D. magna across traits studied and different metal mixtures (Loureiro et al. 2010; Pavlaki et al. 2011). Data also indicate that interactions between metals may vary from synergistic to antagonistic depending on the metals, properties of contaminants and test species (ShuhaimiOthman and Pascoe 2007; Meyer et al. 2015; Kim et al. 2017).

While numerous studies found a combination of additive or synergistic effects, many studies have found only antagonistic effects. For example, recent research by Pérez and Hoang (2018) on mixture toxicity to D. magna showed that the sub-lethal concentration of $\mathrm{Cd}$ and Ni caused antagonistic effects across traits studied. However, other studies on metal mixture toxicity have reported less than additive effects to $D$. magna (Komjarova and Blust 2008; Meyer et al. 2015; Traudt et al. 2016; Pérez and Hoang 2017, 2018). Mahar and Watzin (2005) examined the impacts of $\mathrm{Cu}, \mathrm{Zn}$, and insecticide mixtures on the survival and reproduction in Ceriodaphnia dubia. It has determined less than additive effect for the binary mixture of $\mathrm{Cu}$ and $\mathrm{Zn}$ on survival, but more than additive effect on reproduction. Further, an antagonistic effect was observed on reproductive activity of C. dubia under exposure to high concentrations of benzalkonium chloride with binary mixtures of anticancer drugs, but additive effects in all mixtures at low concentrations (Russo et al., 2018).

Our research, and that of others noted above, highlights that if we are to move towards generalising and predicting the effect of multiple stressors, experiments need to account not only for the diversity of traits that can be evaluated but also for context defined by the metal identity, concentrations, food levels and genotype.

Interestingly, apart from reproduction, our data show that the effects of metals rarely varied among our three genotypes. While three genotypes is certainly too few to generalise about the nature of genetic variation, the data suggests that we should assess whether uniformity in responses to metals is more common than say, to food or predation. Baird et al. (1990) found small differences among D. magna genotypes in response to chronic $\mathrm{Cd}$ and 3,4-dichloroanilin. These responses may be related to specific mechanisms of heavy metals (e.g. metallothionein versus detoxification). In contrast, Barata, et al. (2001) suggested that differences in D. magna genotypes' response to ethyl parathion was due to genetic differences in tolerance.

\section{Conclusion}

Our data indicate that the effect of $\mathrm{Cu}$ on ingestion rate and life history of $D$. pulex depend on $\mathrm{Cd}$, and that metal effects vary by food levels and genotypes. Despite the pervasive presence of interactions on these traits, the overall picture is that combined metals are worse for the daphnid performance than single metals. We also found that the effects of metals on $D$. pulex varied by food levels in the ingestion rate and size at maturity, but much less so by genotype (reproduction only). This study supports the increasingly called for assessment of multiple performance measures (feeding and life history) under multiple stressors (natural and anthropogenic) and among naturally occurring genotypes from the wild.

Acknowledgements This paper is a part of an ecotoxicological research on metals mixtures/PhD degree at the University of Sheffield.

Funding information Financial support was provided by The Ministry of Higher Education and Scientific Research, Iraq.

\section{Compliance with ethical standards}

Conflict of interest The authors declare that they have no conflict of interest.

\section{Appendix}

\section{A. Nominal and actual concentrations of copper and cadmium}

Throughout the experiments using metals, nominal concentrations of 5,10 and $25 \mu \mathrm{g} / \mathrm{L}$ of copper(II) chloride dehydrate and concentrations of $0.5,1$ and $2 \mu \mathrm{g} / \mathrm{L}$ of cadmium(II) dehydrate chloride (Fisher Scientific, UK) were delivered in aqueous solution. To prepare metals stock solutions, analytical grade dihydrous $\mathrm{Cu}$ and $\mathrm{Cd}$ were dissolved in distilled water.

Chronic exposure tests were performed in accordance with the standard protocol OECD Daphnia $s p$., No. 212 (OECD, 2012). Neonates of D. pulex $(<24 \mathrm{~h})$, each individual in $100-\mathrm{mL}$ glass jar containing $50 \mathrm{~mL}$ of hard ASTM, were exposed to the metals over 21 days with media replaced daily. 
We assessed our realised concentrations in the media, in glass jars with algae concentrations at the 'standard food' ration (see 'Material and methods') using inductively coupled plasma mass spectrometry (ICP-MS). For each metal, realised concentrations were equal to the nominal concentrations. The best-fitting regression line predicts realised concentration $=$ $0.84+0.94 *$ nominal concentration (Fig 6; $R^{2}=0.99, F=$ $1913, p<0.002)$. For $C d$, realised concentration $=-0.09+1.3$ $*$ nominal concentration (Fig 7; $R^{2}=0.98, F=996, p<$ $0.002)$.
Fig. 7 The nominal vs. Actual concentrations for $\mathrm{Cu}$ and $\mathrm{Cd}$

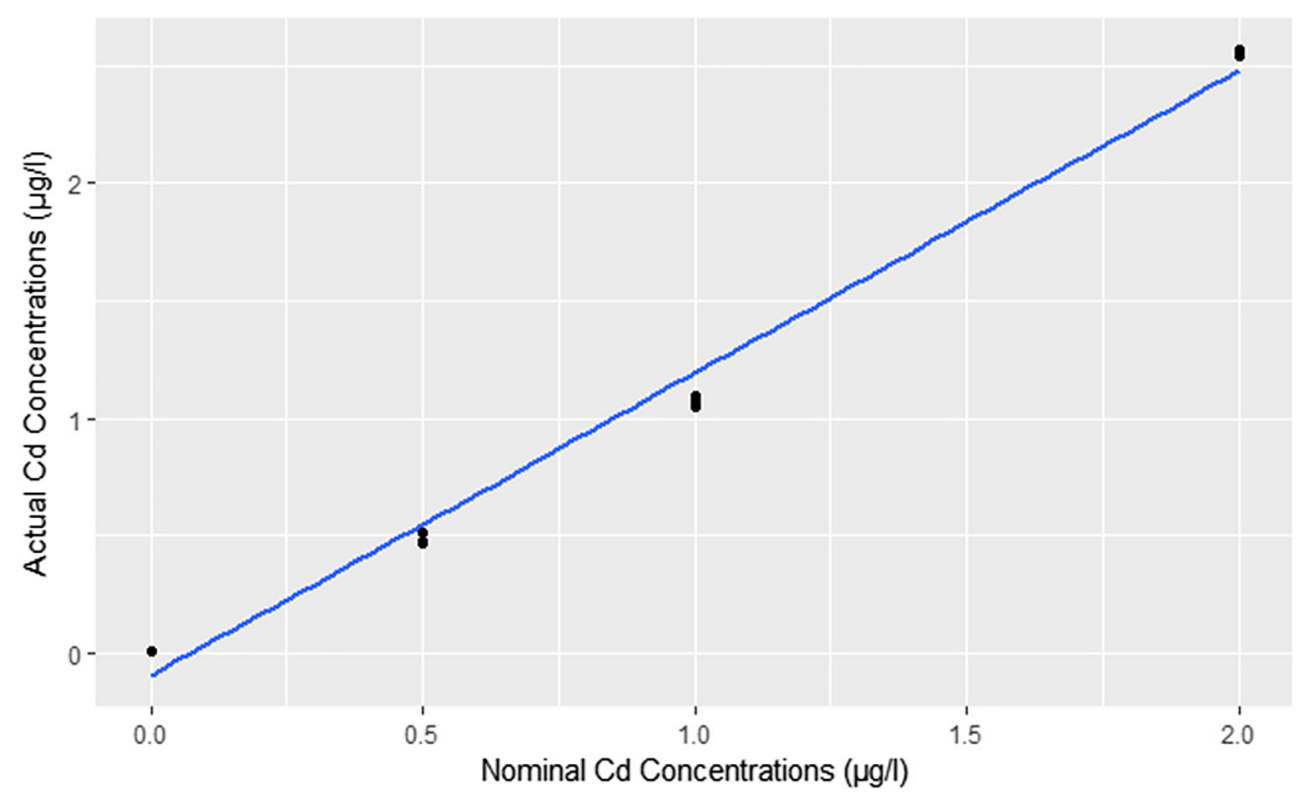

Fig. 6 The nominal vs. Actual concentrations for $\mathrm{Cu}$ and $\mathrm{Cd}$

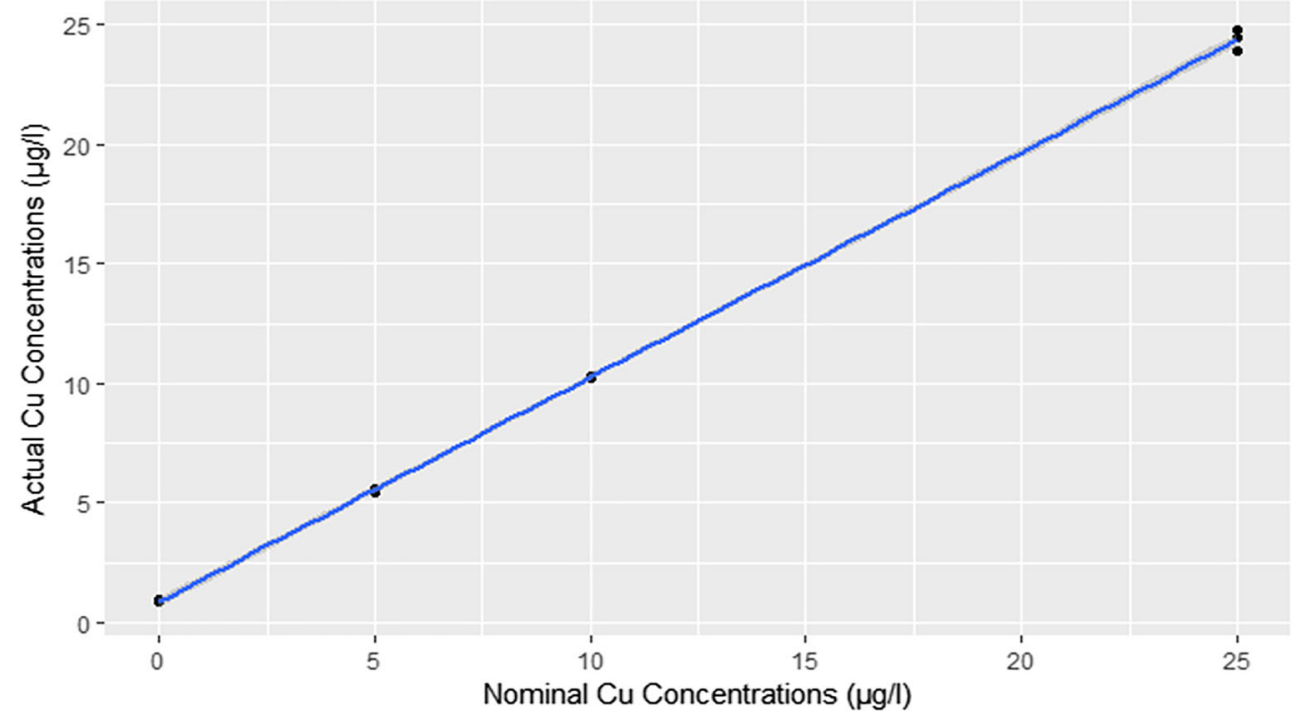




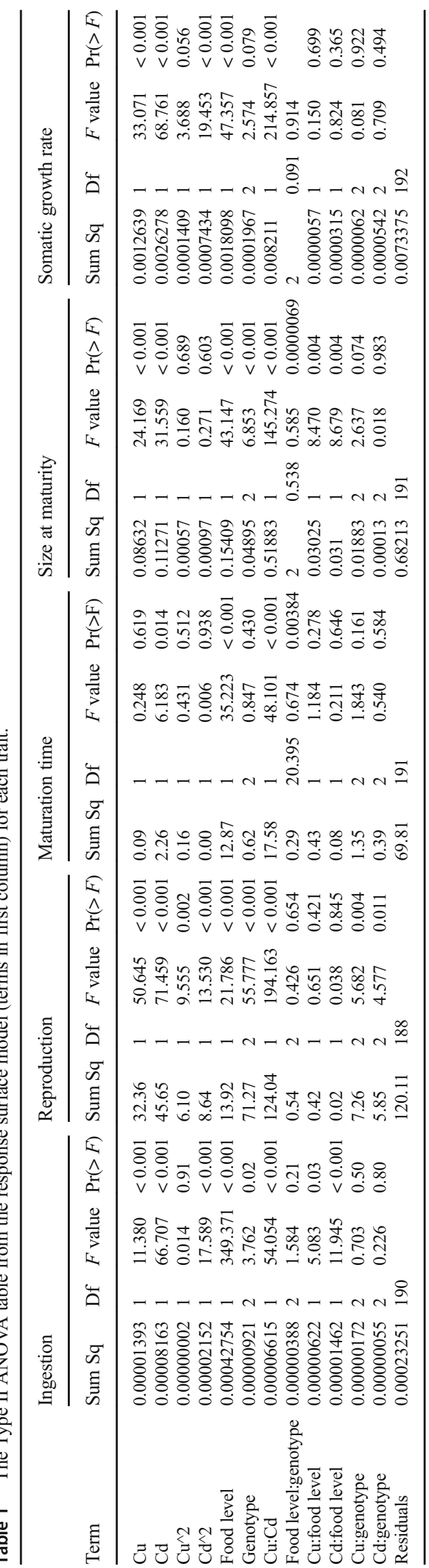

Open Access This article is distributed under the terms of the Creative Commons Attribution 4.0 International License (http:// creativecommons.org/licenses/by/4.0/), which permits unrestricted use, distribution, and reproduction in any medium, provided you give appropriate credit to the original author(s) and the source, provide a link to the Creative Commons license, and indicate if changes were made.

\section{References}

Agra AR, Soares AMVM, Barata C (2011) Life-history consequences of adaptation to pollution. "Daphnia longispina genotypes historically exposed to copper". Ecotoxicology 20:552-562

Altenburger R, Backhaus T, Boedeker W, Faust M, Scholze M (2013) Simplifying complexity: mixture toxicity assessment in the last 20 years. Environ Toxicol Chem 32:1685-1687

Baird DJ, Barber I, Calow P (1990) Clonal variation in general responses of Daphnia magna Straus to toxic stress: I. Chronic life history effects. Funct Ecol 4:399-407

Baird DJ, Barber I, Bradley M, Soares AMVM, Calow P (1991) A comparative study of genotype sensitivity to acute toxic stress using genotypes of Daphnia magna Straus. Ecotoxicol Environ Saf 21: 257-265

Barata C, Baird DJ (2000) Determining the ecotoxicological mode of action of chemicals from measurements made on individuals: results from instar-based tests with Daphnia magna Straus. Aquat Toxicol 48:195-209

Barata C, Markich SJ, Baird DJ (1998) Influence of genetic and environmental factors on the tolerance of Daphnia magna Straus to essential-non-essential metals. Aquat Toxicol 42:115-137

Barata C, Baird DJ, Soares AMVM, Guilhermino L (2001) Biochemical factors contributing to response variation among resistant and sensitive genotypes of Daphnia magna Straus exposed to ethyl parathion. Ecotoxicol Environ Saf 49:155163

Barata C, Markich SJ, Baird DJ, Taylor G, Soares AMVM (2002) Genetic variability in sublethal tolerance to mixtures of cadmium and zinc in genotypes of Daphnia magna Straus. Aquat Toxicol 60: $85-99$

Barata C, Baird DJ, Nogueira AJA, Soares AMVM, Riva MC (2006) Toxicity of binary mixtures of metals and pyrethroid insecticides to Daphnia magna Straus. Implications for multi-substance risks assessment. Aquat Toxicol 78:1-14

Beckerman AP, Wieski K, Baird DJ (2007) Behavioural versus physiological mediation of life history under predation risk. Oecologia 152: 335-343

Beckerman AP, Rodgers GM, Dennis SR (2010) The reaction norm of size and age at maturity under multiple predator risk. J Anim Ecol 79:1069-1076

Bellavere C, Gorbi J (1981) A comparative analysis of acute toxicity of chromium, copper and cadmium to Daphnia magna, Biomphalaria glabrata, and Brachydanio rerio. Environ Technol Lett 2:119-128

Berenbaum MC (1981) Criteria for analyzing interactions between biologically active agents. Adv Cancer Res 35:269-335

Bossuyt BTA, Janssen CR (2004) Influence of multi-generation acclimation to copper on tolerance, energy reserves and homeostasis of Daphnia magna Straus. Environ Toxicol Chem 23:2029-2037

Bridges CC, Zalups RK (2005) Molecular and ionic mimicry and the transport of toxic metals. Toxicol Appl Pharmacol 204:274-308

Brix KV, Deforest DK, Adams WJ (2001) Assessing acute and chronic copper risks to freshwater aquatic life using species sensitivity distribution for different taxonomic groups. Environ Toxicol Chem 20: 1846-1856

Brzóska MM, Moniuszko-Jakoniuk J (2001) Interactions between cadmium and zinc in the organism. Food Chem Toxicol 39:967-980 
Bui T-KL, Do-Hong LC, Dao T-S, Hoang TC (2016) Copper toxicity and the influence of water quality of Dongnai River and Mekong River waters on copper bioavailability and toxicity to three tropical species. Chemosphere 144:872-878

Calow P (1991) Physiological costs of combating chemical toxicants: ecological implications. Comp Biochem Physiol C Comp Pharmacol 100:3-6

Canli M (2006) Effects of copper pre-exposure routes on the energy reserves and subsequent copper toxicity in Daphnia magna. Environ Toxicol 21:521-527

Cedergreen N, Christensen AM, Kamper A, Kudsk P, Mathiassen S, Streigig JC, Sørensen H (2008) A review of independent action compared to concentration addition as reference models for mixtures of compounds with different molecular target sites. Environ Toxicol Chem 27(7):1621-1632

Colbourne JK, Pfrender ME, Gilbert D, Thomas WK, Tucker A, Oakley TH, Tokishita S, Aerts A, Arnold GJ, Basu MK et al (2011) The ecoresponsive genome of Daphnia pulex. Science 331:555-561

Dennis SR, Carter MJ, Hentley WT, Beckerman AP (2011) Phenotypic convergence along a gradient of predation risk. Proc R Soc B 278: $1687-1696$

Durou C, Mouneyrac C, Amiard-Triquet C (2005) Tolerance to metals and assessment of energy reserves in the polychaete Nereis diversicolor in clean and contaminated estuaries. Environ Toxicol 20:23-31

Ebert group, Zoologisches Institut Evolutionsbiologie, Switzerland. http://evolution.unibas.ch/ebert/research/

Feng J, Gao Y, Ji Y, Zhu L (2018) Quantifying the interactions among metal mixtures in toxicodynamic process with generalized linear model. J Hazard Mater 345:97-106

Fernández-Gonzáles MA, Gonzáles-Barrientos J, Carter MJ, RamosJiliberto R (2011) Parent-to-ofspring transfer of sublethal effects of copper exposure: metabolic rate and life-history traits of Daphnia. Rev Chil Hist Nat 84:195-201

Ferrando MD, Andreu E (1993) Feeding behavior as an index of copper stress in Daphnia magna and Brachionus calyciflorus. Comp Biochem Physiol C Pharmacol Toxicol Endocrinol 106(2):327-331

Ferreira ALG, Loureiro S, Soares AMVM (2008) Toxicity prediction of binary combinations of cadmium, carbendazim and low dissolved oxygen on Daphnia magna. Aquat Toxicol 89:28-39

Gama-Flores JL, Sarma SSS, Nandini S (2006) Effect of cadmium level and exposure time on the competition between zooplankton species Moina macrocopa (Cladocera) and Brachionus calyciflorus (Rotifera). J. Environ. Sci. Health Part A 41:1057-1070

Griffitt RJ, Luo J, Gao J, Bonzongo J-C, Barber DS (2008) Effect of particle composition and species on toxicity of metallic nanomaterials in aquatic organisms. Environ Toxicol Chem 27(9): 1972-1978

Guan R, Wang W-X (2006) Comparison between two genotypes of Daphnia magna: effects of multigenerational cadmium exposure on toxicity, individual fitness, and biokinetics. Aquat Toxicol 76: 217-229

Hooper HL, Connon R, Callaghan A, Maund SJ, Liess M, Duquesne S, Hutchinson TH, Moggs J, Sibly RM (2006) The use of image analysis to estimate population growth rate in Daphnia magna. J Appl Ecol 43(4):828-834

Khuri AI, Cornell JA (1996) Responses surfaces: design and analyses, 2nd edn. Marcel Dekker, Monticello

Kim D, Chae Y, An Y-J (2017) Mixture toxicity of nickel and microplastics with different functional groups on Daphnia magna. Environ Sci Technol 51:12852-12858

Komjarova I, Blust R (2008) Multi-metal interactions between $\mathrm{Cd}, \mathrm{Cu}$, $\mathrm{Ni}, \mathrm{Pb}$, and $\mathrm{Zn}$ in water flea Daphnia magna, a stable isotope experiment. Aquat Toxicol 90:138-144
Lari E, Gauthier P, Mohaddes E, Pyle GG (2017) Interactive toxicity of $\mathrm{Ni}, \mathrm{Zn}, \mathrm{Cu}$, and $\mathrm{Cd}$ on Daphnia magna at lethal and sub-lethal concentrations. J Hazard Mater 334:21-28

Laskowski, R., Bednarska, A.I., Kramarz, P.E., Loureiro, S., Scheil, V., Kudlek, J., Holmstrup, M., 2010. Interactions between toxic chemicals and natural environmental factors -a meta-analysis and case studies. Sci Total Environ 408, 3763-3774.

Lind PR, Jeyasingh PD (2015) Genotypic differences in phosphorus use physiology in producers (Chlamydomonas reinhardtii) and consumers (Daphnia pulex) interact to alter primary and secondary production. Evol Ecol 29:551-563

Loureiro S, Svendsen C, Ferreira ALG, Pinheiro C, Ribeiro F, Soaresy AMVM (2010) Toxicity of three binary mixtures to Daphnia magna: comparing chemical modes of action and deviations from conceptual models. Environ Toxicol Chem 29(8):1716-1726

Magos L, Webb M (1978) Theoretical and practical considerations on the problem of metal-metal interaction. Environ Health Perspect 25: $151-154$

Mahar AM, Watzin MC (2005) Effects of metal and organophospate mixtures on Ceriodaphnia dubia survival and reproduction. Environ Toxicol Chem 24:1579-1586

Meyer JS, Ranville JF, Pontasch M, Gorsuch JW, Adams WJ (2015) Acute toxicity of binary and tertiary mixtures of $\mathrm{Cd}, \mathrm{Cu}$ and $\mathrm{Zn}$ to Daphnia magna. Environ Toxicol Chem 34:799-808

Monserrat JM, Martínez PE, Geracitano LA, Amado LL, Martins CMG, Pinho GLL, Chaves IS, Ferreira-Cravo M, Ventura-Lima J, Bianchini A (2007) Pollution biomarkers in estuarine animals: critical review and new perspectives. Comp Biochem Physiol C Toxicol Pharmacol 146:2221-2234

Muyssen BTA, Janssen CR (2001) Zinc acclimation and its effect on the zinc tolerance of Raphidocelis subcapitata and Chlorella vulgaris in laboratory experiments. Chemosphere 45:507-514

Muyssen BTA, Janssen CR (2010) Combined cadmium and temperature acclimation in Daphnia magna: physiological and sub-cellular effects. Ecotoxicol Environ Saf 73:735-742

Nzengue Y, Candéias SM, Sauvaigo S, Douki T, Favier A, Rachidi W, Guiraud P (2011) The toxicity redox mechanisms of cadmium alone or together with copper and zinc homeostasis alteration: its redox biomarkers. J Trace Elem Med Biol 25:171-180

OECD 2012. OECD guideline for testing of chemicals - Daphnia magna reproduction test. Experimental guideline No.211, OECD.

Pavlaki MD, Pereira R, Loureiro S, Soares AMVM (2011) Effects of binary mixtures on the life traits of Daphnia magna. Ecotoxicol Environ Saf 74:99-110

Pérez E, Hoang TC (2017) Chronic toxicity of binary-metal mixtures of cadmium and zinc to Daphnia magna. Environ Toxicol Chem 36: 2739-2749

Pérez E, Hoang TC (2018) Responses of Daphnia magna to chronic exposure of cadmium and nickel mixtures. Chemosphere 208: 991-1001

Piscia R, Colombini M, Ponti P, Bettinetti R, Monticelli D, Rossi V, Manca M (2015) Lifetime response of contemporary versus resurrected Daphnia galeata Sars (Crustacea, Cladocera) to $\mathrm{Cu}$ (II) chronic exposure. Bull Environ Contam Toxicol 94:46-51

R Core Team (2013) R: A language and environment for statistical computing. R Foundation for Statistical Computing, Vienna, Austria http://www.R-project.org.

Reger, J., 2013. The quantitative genetic basis of inducible defences and life-history plasticity in Daphnia pulex. PhD thesis. Sheffield University.

Reger J, Lind MI, Robinson MR, Beckerman AP (2018) Predation drives local adaptation of phenotypic plasticity. Nat Ecol Evol 2:100-107

Rodea-Palomares I, González-Pleiter M, Martín-Betancor K, Rosal R, Fernández-Piñas F (2015) Additivity and interactions in ecotoxicity of pollutant mixtures: Some patterns, conclusions, and open questions. Toxics 3:342-369 
Russo C, Kundi M, Lavorgna M, Parrella A, Isidori M (2018) Benzalkonium chloride and anticancer drugs in binary mixtures: reproductive toxicity and genotoxicity in the freshwater crustacean Ceriodaphnia dubia. Arch Environ Contam Toxicol 74:546-556

Sadeq SS, Beckerman AP (2019) The chronic effects of copper and cadmium on life history traits across Cladocera species: a meta-analysis. Arch Environ Contam Toxicol 76:1-16

Sarma SSS, Nandini S (2006) Review of recent ecotoxicological studies on cladocerans. J Environ Sci Health Part B 41:1417-1430

Shanker AK (2008) Mode of action and toxicity of trace elements. In: Prasad MNV (ed) Trace elements as contaminants and nutrients: consequences in ecosystems and human health. John Wiley \& Sons, Inc., Hoboken, pp 525-555

Shaw JLA, Judy JD, Kumar A, Bertsch P, Wang M-B, Kirby JK (2017) Incorporating transgenerational epigenetic inheritance into ecological risk assessment frameworks. Environ Sci Technol 51(17):94339445

Shuhaimi-Othman M, Pascoe D (2007) Bioconcentration and depuration of copper, cadmium and zinc mixtures by the freshwater amphipod Hyalella azteca. Ecotoxicol Environ Saf 66:29-35

Shuhaimi-Othman M, Nadzifah Y, Ahmad AK (2010) Toxicity of copper and cadmium to freshwater fshes. World Acad Sci Eng Technol 65: 869-871
Soares AMVM, Baird DJ, Calow P (1992) Interclonal variation in the performance of Daphnia magna Straus in chronic bioassays. Environ Toxicol Chem 11:1477-1483

Stohs SJ, Bagchi D (1995) Oxidative mechanisms in the toxicity of metal ions. Free Radic Biol Med 18:321-336

Traudt EM, Ranville JF, Smith SA, Meyer JS (2016) A test of the additivity of acute toxicity of binary-metal mixtures of $\mathrm{Ni}$ with $\mathrm{Cd}, \mathrm{Cu}$, and $\mathrm{Zn}$ to Daphnia magna, using the inflection point of the concentration-response curves. Environ Toxicol Chem 35:18431851

Vijver MG, Elliott EG, Peijnenburg WJGM, De Snoo GR (2011) Response predication for organisms water-exposed to metal mixtures: a meta-analysis. Environ Toxicol Chem 30(6):1482-1487

Zalups RK (2000) Molecular interactions with mercury in the kidney. Pharmacol Rev 52:113-143

Zalups RK, Ahmad S (2003) Molecular handling of cadmium in transporting epithelia. Toxicol Appl Pharmacol 186:163-188

Publisher's note Springer Nature remains neutral with regard to jurisdictional claims in published maps and institutional affiliations. 